\title{
A Generic Mechanism for Perceptual Organization in the Parietal Cortex
}

\author{
(DPablo R. Grassi, ${ }^{1,2,3}$ Natalia Zaretskaya, ${ }^{1,2,3,4}$ and ${ }^{\circledR A n d r e a s ~ B a r t e l s ~}{ }^{1,2,3}$ \\ ${ }^{1}$ Centre for Integrative Neuroscience, ${ }^{2}$ Department of Psychology, University of Tübingen, 72076 Tübingen, Germany, ${ }^{3}$ Max Planck Institute for Biological \\ Cybernetics, 72076 Tübingen, Germany, and ${ }^{4}$ Institute of Psychology, University of Graz, 8010 Graz, Austria
}

Our visual system's ability to group visual elements into meaningful entities and to separate them from others is referred to as scene segmentation. Visual motion often provides a powerful cue for this process as parallax or coherence can inform the visual system about scene or object structure. Here we tested the hypothesis that scene segmentation by motion cues relies on a common neural substrate in the parietal cortex. We used fMRI and a set of three entirely distinct motion stimuli to examine scene segmentation in the human brain. The stimuli covered a wide range of high-level processes, including perceptual grouping, transparent motion, and depth perception. All stimuli were perceptually bistable such that percepts alternated every few seconds while the physical stimulation remained constant. The perceptual states were asymmetric, in that one reflected the default (nonsegmented) interpretation, and the other the non-default (segmented) interpretation. We confirmed behaviorally that upon stimulus presentation, the default percept was always perceived first, before perceptual alternations ensued. Imaging results showed that across all stimulus classes perceptual scene-segmentation was associated with an increase of activity in the posterior parietal cortex together with a decrease of neural signal in the early visual cortex. This pattern of activation is compatible with predictive coding models of visual perception, and suggests that parietal cortex hosts a generic mechanism for scene segmentation.

Key words: bistable perception; fMRI; parietal cortex; pattern motion; perceptual organization; predictive coding

\section{Significance Statement}

Making sense of cluttered visual scenes is crucial for everyday perception. An important cue to scene segmentation is visual motion: slight movements of scene elements give away which elements belong to the foreground or background or to the same object. We used three distinct stimuli that engage visual scene segmentation mechanisms based on motion. They involved perceptual grouping, transparent motion, and depth perception. Brain activity associated with all three mechanisms converged in the same parietal region with concurrent deactivation of early visual areas. The results suggest that posterior parietal cortex is a hub involved in structuring visual scenes based on different motion cues, and that feedback modulates early cortical processing in accord with predictive coding theory.

\section{Introduction}

A fundamental task of our visual system is to make sense of complex visual scenes. This feat involves grouping visual elements

Received Feb. 16, 2018; revised May 29, 2018; accepted June 21, 2018.

Author contributions: P.R.G. wrote the first draft of the paper; P.R.G., N.Z., and A.B. edited the paper; P.R.G., N.Z., and A.B. designed research;P.R.G. and N.Z. performed research;P.R.G. and N.Z. analyzed data; P.R.G. and A.B. wrote the paper.

This work was supported by the German Excellence Initiative of the German Research Foundation (DFG) Grant EXC307, by DFG Grant BA4914/1-1 to A.B., and by the Max Planck Society, Germany. We thank Therese Andrae for her assistance with the collection of the data.

The authors declare no competing financial interests.

Correspondence should be addressed to either Pablo R. Grassi or Andreas Bartels, Vision and Cognition Lab, Centre for Integrative Neuroscience, University of Tübingen, Otrfried-Müller-Str. 25, 72076 Tübingen, Germany, E-mail:Pablo.grassi@cin.uni-tuebingen.de or andreas.bartels@tuebingen.mpg.de.

DOI:10.1523/JNEUROSCI.0436-18.2018

Copyright $\odot 2018$ the authors $\quad 0270-6474 / 18 / 387158-12 \$ 15.00 / 0$ into objects, foreground and background, or other coherent units. Visual motion provides a prominent segmentation cue due to the $3 \mathrm{D}$ nature of our environment: small head- or object-movements give away which visual elements belong to the same object, occluder, or depth-level, and hence aide scene segmentation.

Prior knowledge of likely scene configurations clearly helps in this process. Scene segmentation can hence be thought of as an inference process in which bottom-up sensory information is combined with top-down prior knowledge to predict the most probable cause of the sensory inputs; a definition equivalent to the theory of predictive coding (Rao and Ballard, 1999; Friston, 2005). Within this predictive coding framework, during scene segmentation higherlevel visual areas send top-down signal to the early visual cortex via feedback projections. However, the higher-level neural sources of the feedback signal mediating segmentation are largely unknown. 
A
Plaid

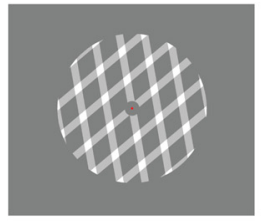

default: pattern motion

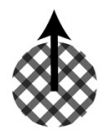

alternative: component motion

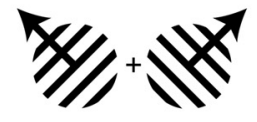

B

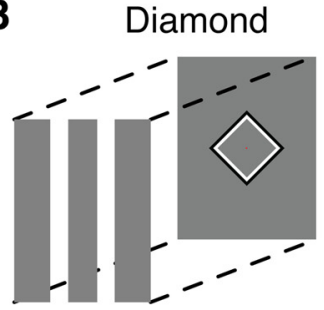

default: unbound elements

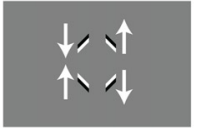

alternative: bound shape

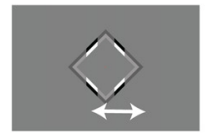

C

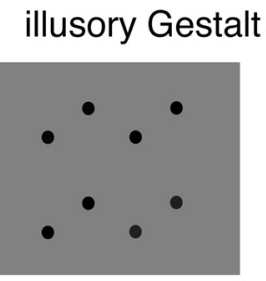

default: unbound elements

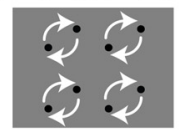

alternative: global Gestalt

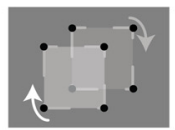

Figure 1. Illustration of the asymmetric bistable stimuli used. $\boldsymbol{A}$, Plaid stimulus. This stimulus could be perceived either as a single plaid moving upward (default percept) or as two depth-separated transparent gratings sliding over each other in opposite directions (alternative percept). $\boldsymbol{B}, 0$ ccluded diamond stimulus and its two interpretations: local vertical motion of separate elements (default percept) and global horizontal motion of a bound shape (alternative percept). C, Illusory Gestalt display used previously (Zaretskaya et al., 2013): four pairs of dots moving circularly in phase could be perceived either as local motion of separate pairs of dots (default percept) or as of two illusory squares sliding over each other in planar motion (alternative percept).

Prior studies focused primarily on the role of early or featureselective visual regions in perceptual organization, such as the motion responsive V5+/ $\mathrm{MT}+$ complex (S. O. Murray et al., 2003; Muckli et al., 2005) or the shape responsive lateral occipital complex (LOC; S. O. Murray et al., 2002). The role of parietal cortex in scene segmentation has been by far less studied, even though clinical and experimental studies have shown that its disruption impairs grouping of visual items into a whole (Wolpert, 1924; Luria, 1959; Karnath et al., 2000; Himmelbach et al., 2009; Romei et al., 2011), and recent magnetoencephalography evidence points to parietal cortex as initiating global shape detection, causally modulating early visual cortex subsequently (Liu et al., 2017).

Of the few previous studies examining a role of parietal cortex in scene segmentation, almost all either used visual stimuli that differed physically between conditions (Paradis et al., 2000; S. O. Murray et al., 2003; Yokoi and Komatsu, 2009; Zeki and Stutters, 2013), compared different attentional states and tasks (Fink et al., 1996; Mevorach et al., 2006; Romei et al., 2011), or examined a singular specialized stimulus that did not allow for generalization (Zaretskaya et al., 2013; Grassi et al., 2016; Liu et al., 2017).

In this study we tested the hypothesis that parietal cortex is invariably involved in visual motion-based perceptual scene segmentation. We used a battery of stimuli that involved entirely distinct aspects of scene segmentation with or without the emergence of Gestalt, including perceptual grouping, occlusion, and transparent motion. Importantly, all stimuli were asymmetrically bistable, such that observers perceived either a default (2D) or an alternative (3D segmented) interpretation. Such asymmetric bistable stimuli provide an ideal means to study scene segmentation: processes related to subjectively experienced scene segmentation can be tracked while physical stimulus properties stay constant and are thus fully controlled for. We examined behavioral responses and associated brain activity during viewing of three bistable displays, involving a wide range of scene interpretations, ranging from emerging shapes (moving occluded diamond vs moving elements), depth-structure (plaid vs compo-

\section{Materials and Methods}

\section{Subjects}

For the diamond and plaid experiments, a total of 18 volunteers (mean age $26.2 \pm 2.9 \mathrm{SD}, 11$ female, 7 male) participated in the study after signing an informed consent form. All had normal or corrected-tonormal vision and no history of neurological impairments. The study was conducted according to the Declaration of Helsinki and was approved by the ethics committee of the University Clinic Tübingen. One subject was excluded from the analysis based on aberrant behavioral responses and head movement. A further subject was excluded from the Region-of-interest (ROI) analysis of motion selective regions because of technical problems during the acquisition of motion localizer data. Hence, 17 subjects entered the final whole-brain analysis and 16 the motion-selective ROI-based analysis (see Definitions of ROIs). Data for the illusory Gestalt stimulus were acquired in 18 separate participants in our previous study (Zaretskaya et al., 2013).

\section{Asymmetric bistable displays}

The three distinct bistable stimuli are presented in Figure 1: transparent plaids (Stoner et al., 1990), the occluded diamond (Lorenceau and Shiffrar, 1992; S. O. Murray et al., 2002), and the illusory Gestalt display (Anstis and Kim, 2011). All data for the first and second stimuli are novel. For the third stimulus, behavioral analyses shown here are novel, and the previously published functional magnetic resonance imaging (fMRI) data (Zaretskaya et al., 2013) were used here for a new conjunction analysis for all three stimulus sets.

All bistable displays led to perceptual alternations between two different interpretations while the physical stimulation remained constant. Importantly, the present bistable displays were perceptually asymmetric: in the more commonly used symmetric bistable displays, both possible perceptual interpretations are more or less balanced in content and complexity, like two distinct orientations in space (e.g., Necker cube or gratings in binocular rivalry), motion directions (e.g., rotating random-dot sphere), or object-identities (face-vase or old-young woman illusion). In contrast, the perceptual interpretations of the present stimuli were asymmetric or imbalanced in their content. In the following sections, we refer to the two perceptual interpretations as to the "default" and "alternative" percepts, respectively, because these terms can easily be operationally defined as described below. Note though that the default percept re- 
flected a 2D interpretation, whereas the alternative percept implied a 3D spatial arrangement.

When stimuli were adjusted such that both perceptual interpretations were balanced in their perceptual times during prolonged viewing upon stimulus presentation, consistently one of the two interpretations was perceived with much higher probability. This initial percept can be defined as the default percept, as it is based on the initial perceptual processes, whereas the "non-default" or alternative interpretation is based on scene segmentation processes that follow after some time. These observations have been previously described for the plaid display (Hupé and Rubin, 2003). Only indirect evidence consistent with this has been reported for the diamond display in that during short stimulus presentations shape perception was difficult and was facilitated only under specific parameters (e.g., peripheral vision; Lorenceau and Shiffrar, 1992). However, in contrast to this observation, a previous fMRI study using different variations of the diamond stimulus did not find any systematic preference for a particular percept (Caclin et al., 2012). For the illusory Gestalt display the local percept was previously reported to occur with higher-than-chance probability at stimulus onset (Anstis and Kim, 2011).

Our first analysis was hence a behavioral one examining relative frequencies of the first percept type at the onset of stimulus presentation for each of the stimuli, which allowed us to define default and alternative percepts for each stimulus type. Please note that the labeling of the percepts in Figure 1 is based on these behavioral results. Based on previous literature, we optimized each display so that both interpretations achieved approximately equal dominance times during prolonged viewing as described below.

\section{Plaid}

The first bistable display ("plaid") consisted of two rectangular-wave gratings of different orientations moving in opposite directions (Fig. 1A). This bistable stimulus can be seen either as a single pattern moving in one direction or as two segregated gratings sliding over each other, perceived as depth-structured transparent motion. The rectangular gratings were presented through a circular aperture with a diameter of $9.15^{\circ}$ of visual angle. Individual gratings were composed of half-transparent white stripes $\left(0.46^{\circ}\right.$ width, $\left.553 \mathrm{~cd} / \mathrm{m}^{2}\right)$ on a gray background moving with a speed of 0.45 cycles/s. The duty cycle, defined as the width of the stripes divided by the width of one spatial period, was $30 \%$, i.e., white stripes were thinner than the gaps between them. The intersection regions of the rectangular gratings were brighter $\left(646 \mathrm{~cd} / \mathrm{m}^{2}\right)$. The angle between individual grating motion vectors was $60^{\circ}$. The global pattern was moving in an oblique direction $\left(20^{\circ}\right.$ from vertical), which has been shown to help achieve equiprobability between the two percepts (Hupé and Rubin, 2004).

\section{Diamond}

The second display ("diamond") consisted of a black and white contour drawing of a diamond whose four corners were occluded by three vertical bars of the same gray color as the background $\left(369 \mathrm{~cd} / \mathrm{m}^{2}\right.$; Fig. 1B). This stimulus can be perceived as four lines moving independently up and down, but the lines can also be perceived as a bound diamond shape translating horizontally behind three illusory occluders (S. O. Murray et al., 2002). We achieved roughly matched dominance duration times with the following parameters: the diamond moved horizontally at a speed of $1.3^{\circ}$ (13 subjects) or $2^{\circ}$ ( 4 subjects) per second and changed direction every $1.2 \mathrm{~s}$ or $0.8 \mathrm{~s}$, respectively. The sides of the diamond were $5.94^{\circ}$ long and $1^{\circ}$ wide. In the starting position, the center of each corner of the diamond was located at $4.2^{\circ}$ eccentricity from fixation.

\section{Illusory Gestalt}

The illusory Gestalt stimulus consisted of four pair of dots moving inphase on circular paths and has been studied extensively before (Anstis and Kim, 2011; Zaretskaya et al., 2013; Grassi et al., 2016, 2017). The stimulus can be perceived as local motion of individual dots or as two illusory squares sliding over each other in transparent motion (i.e., global Gestalt motion). Individual dots had a size of $0.5^{\circ}$, the radius between dots was $2^{\circ}$ and the distance between each dot par and center was $5^{\circ}$. All dots had the same contrast polarity (either black or white). Between each run, dot-rotation direction and dot-contrast polarity was randomly varied. Mean speed of dot rotation was $2.49 \pm 0.2$ rotation per second. For further details, see Zaretskaya et al. (2013).

\section{Display methods}

Displays were generated using MATLAB 2013a (MathWorks) with Psychtoolbox 3 extensions (Brainard, 1997; Pelli, 1997; Kleiner et al., 2007) and presented using a linearized projector with a resolution of $1920 \times$ 1080 pixels at $60 \mathrm{~Hz}$. The semitransparent screen covered $29 \times 16.5^{\circ}$ visual degrees, and was viewed at $80 \mathrm{~cm}$ via a mirror attached to the head coil.

\section{Procedure and experimental design}

Behavioral acquaintance and $f M R I$ task. All participants underwent a behavioral test before fMRI scanning to ensure that they could perceive and report both perceptual interpretations in all displays. We described both possible percepts and let the participants observe each display for at least 4 min.

During the fMRI experiments, subjects were asked to constantly fixate the central red fixation dot and to report their current spontaneously occurring percept by pressing and holding down one of the two buttons ( 1 for the default percept, 1 for the alternative percept) with their right hand. Participants were instructed not to press any button if unsure of their percept and not to enforce any particular percept.

fMRI paradigm. Each fMRI run was dedicated to one of the display types and consisted of two stimulus presentations of $120 \mathrm{~s}$ each, each followed by a fixation-only block of $20 \mathrm{~s}$. We alternated the stimulus presentation between each fMRI run. Each subject underwent four experimental runs per display type (i.e., 8 runs per participant). In each fMRI run we acquired 243 volumes, including four extra volumes at the beginning of the session to control for T1 equilibration effects. Data for the third display type had been collected in a previous study with the same instructions and similar design (90 s stimulus presentation followed by $15 \mathrm{~s}$ fixation, repeated 4 times in each of 5-6 runs; Zaretskaya et al., 2013).

Post-scan questionnaire. Finally, after the fMRI scan, we asked our subjects to fill in a questionnaire to assess subjective experiences beyond the percept dominances. Among other questions not relevant to this study, the questionnaire contained the following questions: Q1: "How confident are you that your button presses reflected your actual percepts?"; Q2: “Did you try to steer/guide your perception to enforce any particular percept?"; Q3: "Was one of the possible interpretations of the stimulus more difficult to see than the other one?". Each question was rated in a seven-point Likert scale (first question: $1=$ not confident, $7=$ very confident; second and third questions: $1=$ alternative percept, $4=$ neutral, $7=$ default percept). We tested the responses against expected median values by means of Wilcoxon signed rank tests.

\section{MRI data acquisition}

We acquired data for the first two displays on a 3 tesla Siemens Prisma system with a 64-channel head coil. All data were acquired in the same session. Functional data were acquired using a gradient-echo echoplanar imaging (EPI) sequence using T2*-weighted blood oxygenation leveldependent contrast with the following parameters: repetition time $(\mathrm{TR})=2.2 \mathrm{~s}$, echo time $(\mathrm{TE})=30 \mathrm{~ms}$, flip angle $=79^{\circ}$, isotropic voxel size of $3 \times 3 \times 3 \mathrm{~mm}, 36$ slices and a field-of-view (FOV) $192 \times 224 \mathrm{~mm}$ for whole-brain coverage. We also acquired a high-resolution T1weighted anatomical scan of each participant (ADNI, 192 slices, voxel size $1 \mathrm{~mm}^{3}, \mathrm{TR}=2 \mathrm{~s}, \mathrm{TE}=3.06 \mathrm{~ms}, \mathrm{TI}=1.1 \mathrm{~s}$, flip angle $=9^{\circ}, \mathrm{FOV}=$ $232 \times 256 \mathrm{~mm})$. For details of the data acquisition parameters of the third display, see Zaretskaya et al. (2013).

\section{Data analysis}

Behavioral data analysis

Determination of default and alternative percepts. To differentiate between the two percept types when viewing the asymmetric bistable stimuli, we operationally defined the initial percept upon stimulus presentation as 
the default interpretation, and the perceptual interpretation that followed as the alternative interpretation.

In our first analysis we hence examined relative frequencies of the first percept type at the onset of stimulus presentation to define the default and non-default (alternative) percept for all three stimuli. We tested the first percept bias (probability of first percept) against chance $(p=0.5$ ) by means of a one-sample $t$ test. The definition of the default and alternative percept was used for all subsequent analyses. Importantly, all stimuli had been optimized to yield more or less balanced durations of both percept types during prolonged viewing. Behavioral data obtained on the illusory Gestalt stimulus were taken from our previously collected dataset ( $\mathrm{Za}-$ retskaya et al., 2013) and were reanalyzed for the current study to obtain first-percept biases.

Test for percept duration changes over time. We performed two control analyses to test for potential changes in percept durations across runs and within a run that could have biased the fMRI results. In the first control analysis, we performed a $2 \times 4$ repeated-measures ANOVA with the factors "percept" and "run" to test for differences in median percept durations across runs. In the second control analysis, we split each run into two halves and tested for differences between percept durations in the first half compared with the second half by means of a $2 \times 2$ repeatedmeasures ANOVA (factors "percept" and "half"). We treated the total duration of a run as the start of the first percept until the end of the last complete percept. The percept belonging to both halves was excluded from the analysis. The reported $p$ values from the ANOVA analyses were adjusted using a Greenhouse-Geisser correction.

\section{Definition of ROIs}

According to the primary hypothesis of this study we paid particular attention to parietal ROIs, but also to other regions that could potentially exhibit differential modulation for default versus alternative percepts based on the previous literature.

Parietal cortex. First, we specifically wanted to test the involvement of previously identified posterior parietal areas in the organization of ambiguous displays. For the group ROI definition we used fMRI data from our previous study (Zaretskaya et al., 2013). We first identified peaks of activity from the contrast "alternative $>$ default" percept at a threshold of $p<0.001$ (uncorrected), which were located in the left and right anterior intraparietal sulcus. We then defined our ROI as two spheres with $20 \mathrm{~mm}$ radius positioned to include the most activated voxels (center: $x= \pm 26$, $y=-54, z=56$; Zaretskaya et al., 2013).

Early visual cortex. A large number of studies revealed early visual cortex modulations as a function of perceptual interpretations (S. O. Murray et al., 2002; Fang et al., 2008; Grassi et al., 2017). These differential modulations have frequently been interpreted as a signature of feedback signals carrying information about a high-level interpretation. In this context, we decided to examine whether activity related to the alternative versus default interpretation elicited similar responses in early visual cortex for our stimuli. We defined the occipital visual fields V1, V2, and V3 in each subject individually using surface-based probabilistic templates (Wang et al., 2015). For this, we generated cortical surface models of each subject using the FreeSurfer software (Fischl et al., 1999) and projected the maximum probabilistic maps of the topographic areas V1, V2, and V3 from the atlas space onto the individual surfaces. This procedure was done using a virtual container written by Noah C. Benson (https://hub.docker.com/r/nben/occipital_atlas/). Thereafter, we transformed the surface-based ROIs into individual volume space and normalized them into MNI space for $\beta$ estimate extraction. Examples of early visual cortex ROIs are shown in Figure $3 C$.

Shape and motion regions. In addition to the posterior parietal and early visual cortex ROIs, we also investigated the involvement of ventral shape-selective LOC and of dorsal motion selective areas V5/MT, MST, $\mathrm{V} 3 \mathrm{~A}, \mathrm{V6}$, and two recently described motion responsive hubs in the cingulate sulcus (CSv) and precuneus (Pc). Most previous fMRI studies using the diamond display focused their analysis on LOC and excluded dorsal motion-selective and parietal ROIs from their analyses (S. O. Murray et al., 2002; Fang et al., 2008; De-Wit et al., 2012), with the exception of Caclin et al. (2012) who also included the V5+/MT+ complex. On the other hand, fMRI studies using bistable plaid stimuli conducted ROI analyses only on the early visual cortex, dorsal V5+/MT+, and V3A (Castelo-Branco et al., 2002; Villeneuve et al., 2012), thus not including ventral shape-responsive areas or other dorsal motion selective areas.

We defined dorsal motion selective ROIs using standard methods (Huk et al., 2002; Smith et al., 2006; Fischer et al., 2012a) in 16 of 17 subjects (in 1 subject technical problems prevented data acquisition of the motion localizer). Our motion localizer consisted of seven conditions presented in a randomized block design, as described before (Fischer et al., 2012a). Attentional effects were balanced by applying the same letter back-matching task in all conditions (Huk et al., 2001). Using contrasts detailed below we defined a large set of specialized dorsal motion responsive areas: V5/MT, MST, V3A, V6, CSv, and Pc.

The human V5+/MT+ complex was defined as the contralateral response using the contrast of coherent hemifield motion versus static dots. MST + was defined as the respective ipsilateral response (Dumoulin et al., 2000; Huk et al., 2002). Thereafter, we excluded the correspondent MST + voxels from the V5+/MT+ complex to define V5/MT. We use the term MST + as several additional motion responsive satellite regions of monkey V5/MT have receptive fields extending into the ipsilateral hemifield like those of MST that are most likely included in our MST+ (Nelissen et al., 2006; Kolster et al., 2010).

Area V3A was defined as the region below the parietal-occipital sulcus and extending into the transverse occipital sulcus that responded significantly stronger to coherent planar motion with moving fixation disk compared with the moving fixation disk on a static background. This contrast reliably leads to selective activation of voxels overlapping with retinotopically defined V3A (Fischer et al., 2012a).

Areas V6 (Pitzalis et al., 2006; Fischer et al., 2012a), CSv (Wall and Smith, 2008; Fischer et al., 2012b), and Pc (Cardin and Smith, 2010, 2011) were defined using the contrast comparing coherent optic flow to random motion exploiting their established preferences to coherent motion. Note that the region defined here as V6 most likely also includes voxels of the neighboring V6Av as this region also marginally prefers coherent compared with random dot motion (Pitzalis et al., 2013, 2015).

To define ventral shape-selective areas LOC, we used the well established procedure of contrasting images of objects with their Fourierscrambles (Grill-Spector et al., 2001) in 17 subjects. Both blocks of the localizer were repeated 15 times and consisted of 6 images, each presented for $2 \mathrm{~s}$. Subjects were asked to perform an image back-matching task to ensure constant attentional loads across conditions.

Please note that we did not have independently drawn ROIs for the subset of subjects observing the illusory Gestalt stimulus. However, responses of independently defined motion selective areas (V5/MT, MST, V3A, V6) to the illusory Gestalt stimulus have been analyzed previously (Grassi et al., 2016) following a similar procedure and revealed no percept-driven modulation favoring the alternative percept, regardless of stimulus size. Also, whole-brain analyses of responses while viewing the illusory Gestalt stimulus revealed no involvement of ventral shapeselective areas.

\section{MRI data analysis}

Preprocessing. All data were processed using SPM8 (Wellcome Department of Imaging Neuroscience, London, UK). Preprocessing included slice-time correction (reference slice: TR/2), motion correction and spatial normalization using segmentation to the MNI space. For the (singlesubject) ROI analyses, we smoothed the EPI volumes with a Gaussian kernel of $3 \mathrm{~mm}$ full-width at half-maximum (FWHM). For group-level whole-brain analyses, we spatially smoothed the images with a Gaussian kernel of $9 \mathrm{~mm}$.

First level GLM analysis. Data of each subject were analyzed separately for each stimulus using a standard GLM approach. Reports of default and alternative percept onsets were used to build two regressors-of-interest using stick functions. We also included two further regressors modeling the onsets of the fixation-only periods and of the stimulus presentation, the latter to account for possible effects related to the appearance of the stimuli on the screen. We modeled the onsets using the standard "double-gamma" hemodynamic response model (with T0 $=0$ ). Moreover, to account for variability in the hemodynamic response function (HRF) and in the timing of key presses we also included the first temporal 
derivative of each regressor in the model. Finally, we included six nuisance regressors of the realignment parameters to model variance related to head motion and an orthogonalized global mean regressor. Lowfrequency signal drifts were removed using a high-pass filter with $128 \mathrm{~s}$ cutoff.

Group level analysis and derivative boost to account for temporal response variability. We performed two types of analyses at the group level: a region of interest analysis and a whole-brain analysis. To include the variance accounted for by all basis functions (i.e., standard HRF and the first temporal derivative) in these second-level analyses, we used a combination of the magnitude calculated across both $\beta$ estimates called "derivative boost”" (Calhoun et al., 2004; Steffener et al., 2010; Pernet, 2014). The derivative boost is calculated as follows:

$$
H=\sqrt{\beta_{1}^{2} \sum_{t=1}^{N} x_{1}^{2}+\beta_{2}^{2} \sum_{t=1}^{N} x_{2}^{2} * \frac{\beta_{1}}{\left|\beta_{1}\right|},}
$$

with the following parameters: $H$, derivative boost; $\beta_{1}$, parameter estimate for the canonical HRF; $x_{1}$, regressor convolved with the HRF, $\beta_{2}$ parameter estimate for its first derivative; $x_{2}$, regressor convolved with the derivative. We constrained the derivative boost by a time window of $\pm 1 \mathrm{~s}$ relative to the canonical HRF as suggested by Steffener et al., 2010. The code used for boosting the images is available at the repository: https://github.com/CPernet/spmup/blob/master/spmup_hrf_boost.m.

For the ROI analyses, we merged the independently defined ROIs from both hemispheres into one ROI whenever possible. We then extracted the boosted $\beta$ estimates of each condition (i.e., perceptual onset) within each ROI for all subjects. Estimates were averaged over runs and voxels for each ROI. The mean $\beta$ estimates were then transformed to percentage signal change using the respective ROI mean signal as normalization reference (cf. Pernet, 2014).

Paired $t$ tests were conducted across subjects to determine differences between alternative and default percepts for each ROI. For the hypothesis-driven ROI analysis testing the hypothesis that the parietal cortex is activated by motion-based segmentation and that the early visual cortex (EVC) is suppressed by modulatory feedback signals during alternative interpretations we tested template ROIs using one-sided paired $t$ tests. For the exploratory ROI analysis of individually defined midlevel ventral and dorsal regions, two-sided paired $t$ tests were used. Statistics were Holm-Bonferroni corrected for multiple comparisons for the number of tests conducted.

Whole-brain random-effects analyses were used to test the possible involvement of additional regions in perceptual organization. To identify voxels favoring alternative perceptual states, we performed a voxelwise comparison between alternative $>$ default perceptual states in every subject. Based on the boosted contrasts we performed random effects $t$ tests across all participants for each display type separately. To formally test for activations common to all stimuli we performed a conjunction analysis by plotting overlapping voxels from the contrast alternative $>$ default from all stimuli (thresholded at $t=3$ ).

\section{Results}

\section{Behavioral results}

\section{Relative percept frequencies at stimulus onset}

Figure $2 A$ shows relative frequencies of each percept for each of the three stimulus classes. For the plaid stimulus, pattern motion (i.e., a single coherent pattern moving in a single direction) was perceived first upon stimulus presentation with a probability of $93.4 \%$ of the trials $\left(t_{(16)}=13.4, p=4.0772 \mathrm{e}-10\right.$, Cohen's $d=$ 3.25 ). This is consistent with previous observations (Hupé and Rubin, 2003; Hupé and Pressnitzer, 2012). For the diamond stimulus, in accord with our expectations, subjects perceived the four unbound elements upon stimulus presentation in $83.8 \%$ of the trials $\left(t_{(16)}=5.46, p=5.2191 \mathrm{e}-05\right.$, Cohen's $\left.d=1.32\right)$, which later alternated with the grouped percept of a diamond shape moving behind three occluders. For the illusory Gestalt display, $82.8 \%$ of the trials began with the percept of unrelated dot-pairs
A

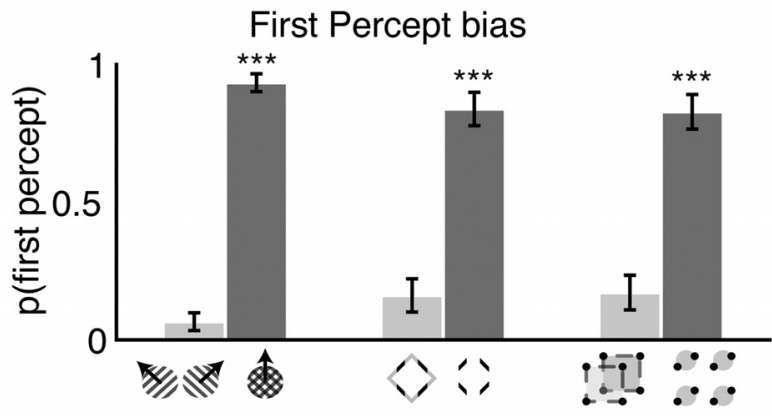

B $\stackrel{\sigma}{\sigma}$ Mean percept durations

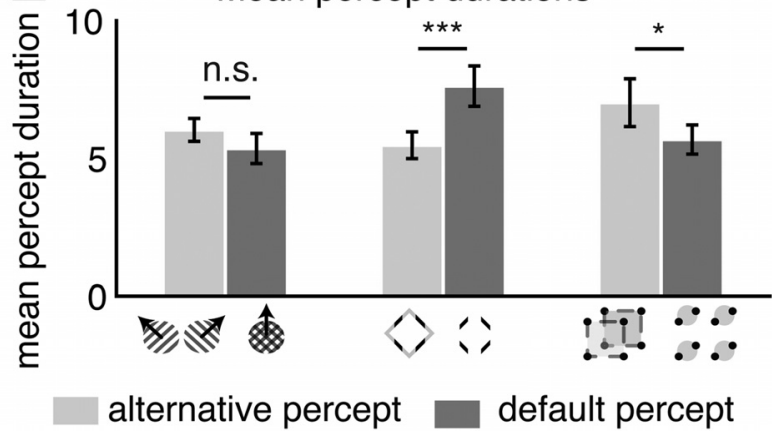

Figure 2. First percept bias and mean percept durations during continuous viewing. $\boldsymbol{A}, \mathrm{Bar}$ plots show the probability for a given percept to be perceived first upon stimulus presentation, for all three bistable stimuli (mean \pm SEM). For all stimuli, one of the two percepts had an overwhelming predominance of being initially perceived. We defined the first percept as the default percept. The right bar plot shows the first percept bias for the Gestalt illusion, which had not been analyzed by Zaretskaya et al. (2013). We statistically tested the first percept bias against chance ( $p=0.5$ ) by means of a one-sample $t$ test. $\boldsymbol{B}$, The bar graphs depict the average perceptual durations for all percepts during continuous viewing (mean \pm SEM). Durations for the illusory Gestalt display were published by Zaretskaya et al. (2013) and are included for completeness. ${ }^{* * *} p<0.001,{ }^{* *} p<0.01,{ }^{*} p<0.05$, uncorrected.

$\left(t_{(17)}=5.21, p=7.2667 \mathrm{e}-05\right.$, Cohen's $\left.d=1.23\right)$, which then alternated with the grouped Gestalt percept. We define the respective first percepts as default percepts (plaid: pattern motion; diamond: unbound elements; Gestalt: local motion). After the initial default interpretation, perceptual alternations with the non-default, alternative interpretation (plaid: transparent component motion; diamond: bound shape; illusory Gestalt: global Gestalt motion) ensued.

These behavioral results suggest that across all stimuli, alternative percepts involved more complex scene segmentation processes compared with the initial default percepts: for the plaid stimulus, perceiving two depth-segmented transparent objects sliding over each other in different directions involves higherlevel processes (depth-organization and transparent motion) compared with perception of a simple pattern moving in one direction. Similarly, the alternative percept of a partially occluded diamond moving behind two invisible columns involves higherlevel processes, as it implies understanding of visual 3D arrangements partly covering a moving object, in contrast to the perception of separately moving lines. The same argument holds for the Gestalt stimulus where the alternative Gestalt percept requires long-range spatial grouping mechanisms that are not required for perception of the local inducers in the default percept.

\section{Relative percept frequencies during prolonged viewing}

Even though we had optimized all of the stimuli to yield balanced durations of both percept types, the average median durations shown in Figure $2 B$ reveal some imbalances, some in favor of the 
default, others in favor of the non-default (alternative) perceptual interpretation. The diamond display yielded longer percept durations for the default interpretation $(7.62 \pm 3.02 \mathrm{~s}$ mean \pm $\mathrm{SD})$ than for the alternative one $\left(5.47 \pm 2.01 \mathrm{~s}, t_{(16)}=5.28, p=\right.$ $7.4994 \mathrm{e}-05$, Cohen's $d=1.28$ ), the plaid display yielded no statistically significant difference between percept types (default: $5.354 \pm 2.26 \mathrm{~s}$, alternative: $6.031 \pm 1.71 \mathrm{~s}, t_{(16)}=1.058, p=$ 0.306 , Cohen's $d=0.26$ ), and the illusory Gestalt display led to longer alternative percept durations $(7.02 \pm 3.69 \mathrm{~s})$ compared with default percept durations $\left(5.68 \pm 2.25 \mathrm{~s}, t_{(17)}=2.46, p=\right.$ 0.025 , Cohen's $d=0.58$; Fig. $2 B$ ). Importantly, the balances during prolonged viewing were not related to the strong predominance of the default percept upon stimulus presentation.

Note that the divergence of average dominance durations across stimuli provided the advantage that any convergent fMRI results across stimuli would hence not be attributable to systematic behavioral bias.

Finally, the distributions of dominance durations were well fitted with gamma functions (maximum likelihood fit coefficient of determination $r^{2}$, all $>0.9$, data not shown).

\section{Percept duration changes over time}

We found a significant increase of the median percept durations across runs in both displays $[2 \times 4$ (percept $\times$ run) repeatedmeasure ANOVA; main effect "run", plaid: $F_{(3,48)}=4.6958, p=$ 0.01755 ; diamond: $\left.F_{(3,48)}=4.3013, p=0.01289\right]$. However, and relevant to our fMRI results, the relation between percepts remained constant across time (interaction: percept $\times$ run, plaid: $F_{(3,48)}=0.091, p=0.961$, diamond: $\left.F_{(3,48)}=2.34, p=0.102\right)$. A second analysis testing for differences between percept durations in the first half of the runs compared with those in the second half of the runs [ $2 \times 2$ (percept $\times$ half) repeated-measures ANOVA] revealed no significant results neither for the main effect nor for the interaction in both displays (all $F<0.2$ and all $p>0.5$ ). Together, these results revealed no differences in relative percept durations over time that could have influenced the fMRI results presented below.

\section{Post-scan questionnaire}

The post-scan questionnaire revealed that subjects were confident in their responses [Q1; Likert range: $1=$ not confident, $7=$ very confident; diamond: $5.94 \pm 1.19$ (mean $\pm \mathrm{SD})$, median $=6$; plaid: $5.7 \pm 1.1($ mean $\pm S D)$, median $=6]$, with no difference against the expected value of 6 (Wilcoxon signed rank test, diamond: $\mathrm{w}=38.5, p=1$; plaid: $\mathrm{w}=25, p=0.2553)$. For the plaid display, most subjects reported they did not try to enforce any particular percept [Q2; Likert range: $1=$ alternative percept, $7=$ default percept; $4 \pm 0.63$ (mean $\pm \mathrm{SD}$ ), median $=4$, Wilcoxon signed rank test against median of $4: \mathrm{w}=3, p=1]$ and no particular percept was more difficult to see than the other one $[\mathrm{Q} 3 ; 3.65 \pm 1.27($ mean $\pm \mathrm{SD})$, median $=4, \mathrm{w}=17.5, p=$ $0.3652]$. For the diamond display, six subjects reported a tendency to have enforced their percepts toward the alternative interpretation during viewing of the diamond display [Q2; $3.56 \pm$ 0.63 (mean $\pm \mathrm{SD})$, median $=4$, Wilcoxon signed rank test against median of $4: \mathrm{w}=0, p=0.03125]$, in line with the fact that subjects reported the alternative percept of the diamond display to be more difficult to see $[\mathrm{Q} 3 ; 3.24 \pm 1.25$ (mean $\pm \mathrm{SD}$ ), median $=3, \mathrm{w}=12.5, p=0.038]$. All responses can be seen in Table 1.

To test whether mental effort as evidenced above could have affected any of our fMRI results we report additional whole-brain control analyses (see control analyses) showing that the above
Table 1. Post-scan questionnaire answers

\begin{tabular}{lllllllllllllllll}
\hline Question & \multicolumn{11}{c}{ Plaid } & 110 \\
\hline Likert scale & 1 & 2 & 3 & 4 & 5 & 6 & 7 & Unsure & 1 & 2 & 3 & 4 & 5 & 6 & 7 & Unsure \\
Q1: Confidence & 0 & 0 & 0 & 3 & 4 & 5 & 5 & 0 & 0 & 0 & 1 & 1 & 3 & 5 & 7 & 0 \\
Q2: Enforce & 0 & 0 & 2 & 13 & 0 & 1 & 0 & 1 & 0 & 1 & 5 & 10 & 0 & 0 & 0 & 1 \\
Q3: Difficult & 0 & 4 & 3 & 7 & 1 & 2 & 0 & 0 & 1 & 4 & 5 & 5 & 1 & 1 & 0 & 0 \\
\hline
\end{tabular}

Shown is the number of participants who chose a given value on a Likert scale, for each of three questions (see Materials and Methods): $Q 1: 1=$ not confident, $7=$ very confident; $Q 2$ and $03: 1=$ alternative percept, $4=$ neutral, $7=$ default percept.

behavioral factors did not account for the main results (see Whole-brain responses).

\section{ROI analysis}

In the following, we describe the results of our ROI analyses for the ROIs of PPC and EVC and for the individually defined ROIs of dorsal motion selective and ventral shape selective areas. Statistical results of all ROI analyses are provided in Table 2.

\section{Posterior parietal cortex and early visual cortex responses}

One of the central questions of the current study was whether the posterior parietal cortex is generally involved in computing the alternative stimulus interpretations across distinct bistable motion stimulus classes. To test the generic role of the PPC in perceptual organization, we defined two parietal ROIs in the left and right parietal cortex using previously reported coordinates ( $\mathrm{Za}-$ retskaya et al., 2013). Moreover, in view of previous studies showing EVC modulations as a function of perceptual states (S. O. Murray et al., 2002; Fang et al., 2008; Zaretskaya et al., 2013; Grassi et al., 2017), we examined percept-specific modulations in three early visual ROIs (V1, V2, and V3) defined using individually inflated brain surfaces and a probabilistic atlas based on functional retinotopy of a large subject population (Wang et al., 2015).

This ROI analysis revealed a highly consistent response pattern for the tested bistable displays. The parietal ROI showed an enhancement of activity for the non-default interpretation compared with the default interpretation in all tested displays (Fig. $3 A$ ). In contrast, early visual ROIs V1 and V2 were consistently suppressed in activity, regardless of the stimulus used (Fig. 3B). We found no percept-driven modulation in visual area V3.

Both results correspond to our previously published findings using the illusory Gestalt stimulus (Zaretskaya et al., 2013; Grassi et al., 2016) that demonstrated a specific involvement of parietal cortex during perception of the non-default Gestalt percept independent of stimulus dimensions, while EVC was suppressed.

Hence, the current findings confirm our hypothesis by demonstrating that across three entirely distinct bistable stimulus classes, parietal cortex consistently responded more strongly to the alternative segmented percept interpretation, while early visual cortex was suppressed.

\section{Responses of motion-selective dorsal regions and shape-selective ventral regions}

Beyond examining our main hypothesis, we also wanted to quantify percept-driven responses of midlevel, functionally specialized dorsal motion- and ventral shape-responsive regions. We therefore defined individual ROIs for every subject using separate functional localizers. The results revealed divergent, i.e., stimulusspecific, differential modulations across the stimulus classes in both visual processing streams.

Shape-selective LOC in the ventral occipital cortex favored the alternative interpretation during viewing of the diamond (i.e., 
Table 2. Results of the paired $t$ test for all ROIs for both stimuli

\begin{tabular}{|c|c|c|}
\hline ROI & Plaid & Diamond \\
\hline \multicolumn{3}{|l|}{ Parietal ROI } \\
\hline PPC & $t_{(16)}=5.79, p=1.374 \mathrm{e}-05, d=1.4^{* * *}$ & $t_{(16)}=2.42, p=0.014, d=0.59^{*}$ \\
\hline \multicolumn{3}{|l|}{ Visual fields } \\
\hline V1 & $t_{(16)}=-5.39, p=0.0001, d=1.31^{* * *}$ & $t_{(16)}=-5.02, p=0.0001, d=1.22^{* * *}$ \\
\hline V2 & $t_{(16)}=-4.65, p=0.0003, d=1.13^{* * *}$ & $t_{(16)}=-3.63, p=0.0023, d=0.88^{* *}$ \\
\hline V3 & $t_{(16)}=-0.7152, p=0.4848, d=0.17$ & $t_{(16)}=0.15, p=0.8847, d=0.04$ \\
\hline \multicolumn{3}{|c|}{ Motion-selective } \\
\hline V5/MT & $t_{(15)}=6.34, p=1.323 \mathrm{e}-05, d=1.59^{* * *}$ & $t_{(15)}=1.63, p=0.1242, d=0.41$ \\
\hline MST & $t_{(15)}=6.19, p=1.703 \mathrm{e}-05, d=1.55^{* * *}$ & $t_{(15)}=3.94, p=0.0013, d=0.98^{* *}$ \\
\hline V3A & $t_{(14)}=3.37, p=0.0046, d=0.87^{*}$ & $t_{(14)}=2.25, p=0.0413, d=0.58+$ \\
\hline V6 & $t_{(15)}=0.71, p=0.4857, d=0.18$ & $t_{(15)}=0.75, p=0.4635, d=0.19$ \\
\hline CSv & $t_{(12)}=0.48, p=0.6382, d=0.13$ & $t_{(12)}=1.28, p=0.2236, d=0.36$ \\
\hline Pc & $t_{(14)}=1.30, p=0.2142, d=0.34$ & $t_{(14)}=1.12, p=0.2831, d=0.29$ \\
\hline \multicolumn{3}{|c|}{ Shape-selective } \\
\hline $\mathrm{LOC}$ & $t_{(16)}=0.69, p=0.4990, d=0.17$ & $t_{(16)}=6.02, p=1.768 \mathrm{e}-05, d=1.46^{* * *}$ \\
\hline
\end{tabular}

$d$ : effect size (Cohen's $d$ ), ${ }^{* * *} p<0.001 ;{ }^{* *} p<0.01 ;{ }^{*} p<0.05$, Holms-Bonferroni corrected; $+p<0.05$, uncorrected.

shape perception), but had no significant preference for either percept of the plaid stimulus (Fig. 4), and intriguingly, it was not involved in the perception of the (non-default) global Gestalt illusion (Zaretskaya et al., 2013; Grassi et al., 2016, 2017). Hence, for shape-selective LOC there was no systematic modulation favoring either default or alternative perceptual interpretations across the stimulus classes.

Also dorsal motion-selective ROIs showed no systematic modulation favoring either default or alternative perceptual interpretations across all stimulus classes. During viewing of the plaid display, V5/MT, MST, and V3A showed an increase of activity with the alternative percept (i.e., transparent motion; Fig. $4 A$ ). During viewing of the diamond display, only area MST showed a differential modulation, favoring the alternative interpretation (i.e., diamond percept). In contrast, a ROI analysis of areas MST, V3A, and V6 showed no differential modulation as a function of percept during viewing of the illusory Gestalt display. Only area V5/MT showed a small selective deactivation during the global Gestalt perception (Grassi et al., 2016).

The stimulus-specific activation patterns in shape-selective ventral and motion-selective dorsal regions indicate that the involvement of these extrastriate areas in resolving perceptual ambiguity depends on the exact stimulus features, in contrast to the fully consistent modulation pattern found in the posterior parietal and early visual cortex across all stimulus classes.

\section{Whole-brain responses}

To investigate whether regions other than those examined in the ROI analyses were involved in perceptual inference and scene segmentation, we performed a whole-brain random-effects analysis. We tested the main contrast alternative percept $>$ default percept and its inverse for each stimulus type. This analysis revealed similar activation maps for all displays (Fig. 5A). To allow for an easy comparison with results for the corresponding contrast of the Gestalt display, we additionally present the wholebrain responses to the illusory Gestalt stimulus from Zaretskaya et al. (2013) (Fig. 5A, bottom), detailed results for which can be found in the study by Zaretskaya et al. (2013), as well as in a replication study with different stimulus sizes in Grassi et al. (2016).

In line with the ROI analysis results we found a consistent activation of the posterior parietal cortex, together with a consistent deactivation of EVC during the perception of the alternative interpretation across all presented stimuli (Fig. 6, conjunction analysis). Peak MNI values $(x, y, z)$ of PPC activity for plaid were $(40,-36,52)$ and $(32,-52,54)$ for the right hemisphere and $(-22,-64,56)$ and $(-28,-44,52)$ for the left hemisphere; for diamond they were $(28,-52,54)$ for the right and $(-34,-40$, 48 ) for the left hemisphere. We also observed differential responses in areas along both, ventral and dorsal visual pathways, but these were not consistent across the different types of stimuli.

\section{Control analyses}

Although participants were instructed not to enforce any particular percept, the bistable paradigm does not fully exclude the possibility of attentional confounds due to differences in mental effort between percepts. We hence performed an additional whole-brain analysis using only subjects who reported after the fMRI session not to have enforced any particular percept (Table 1; diamond: $n=10$, plaid: $n=13$ ). The results replicated those of the original analysis, for both displays (Fig. $5 B$ ).

Second, we examined whole-brain activity of the two participants who reported more difficulty in perceiving the default percept for the diamond display, plus an additional two participants who reported the same for the plaid display (Table 1). Figure $5 C$ shows that in all four participants PPC activity was significantly higher for the alternative versus the default percept, hence ruling out that difficulty drove the PPC results.

Finally, note that a strong argument against attention-related factors driving PPC during the alternative percept is the concurrent relative suppression of V1 and V2, which is not compatible with attentional enhancement.

\section{Discussion}

In this study, we used three asymmetric bistable stimuli to test the hypothesis that particular brain regions are consistently involved in motion-based scene segmentation, regardless of particularities of the percept or physical stimulus properties. While the stimuli differed vastly in their appearance, each of them had one default perceptual interpretation and one alternative interpretation that involved different scene segmentation processes. The stimuli remained physically constant while percepts alternated, and were hence well suited to identify neural substrates underlying perceptual organization. Our results showed that the PPC was consistently activated during perception of the alternative percept across distinct stimulus classes, no matter whether this percept included a Gestalt or whether it increased or decreased the number of perceived items. This PPC activation was systematically 
A

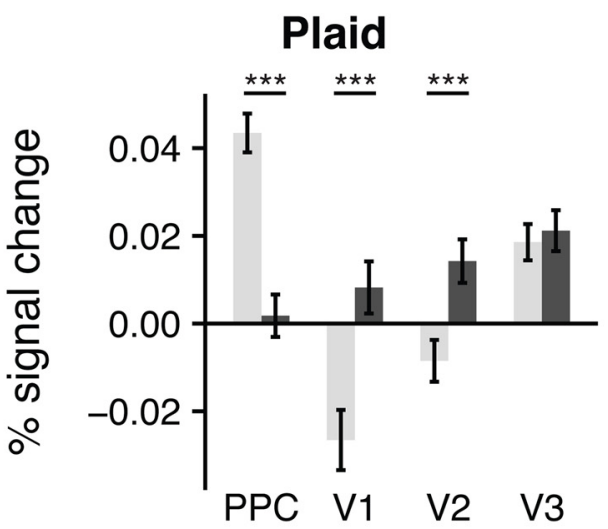

B

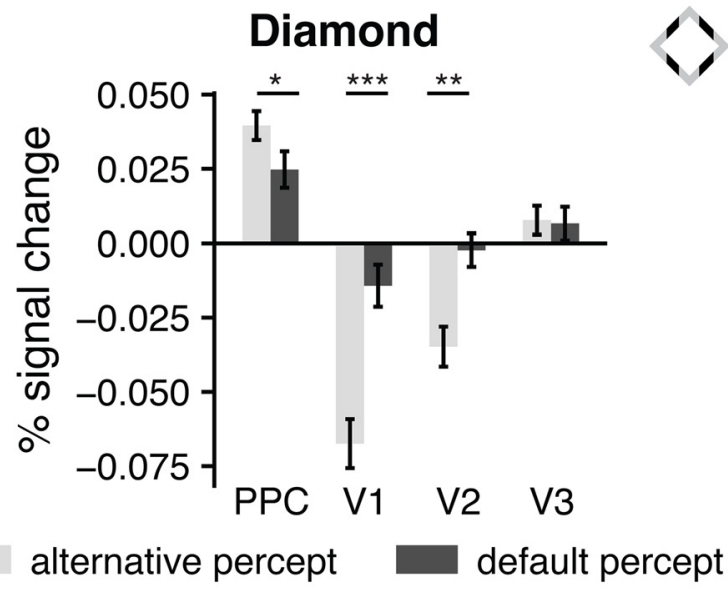

C Parietal and early visual ROls

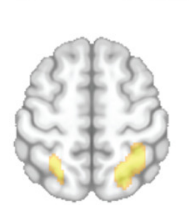

S5

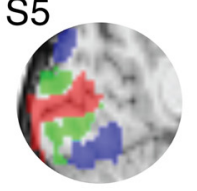

$Z=58$
S8

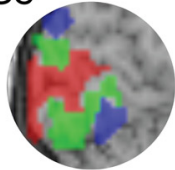

$x=-10$
S10

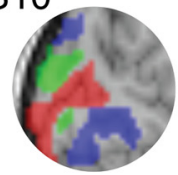

$x=16$
PPC

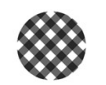

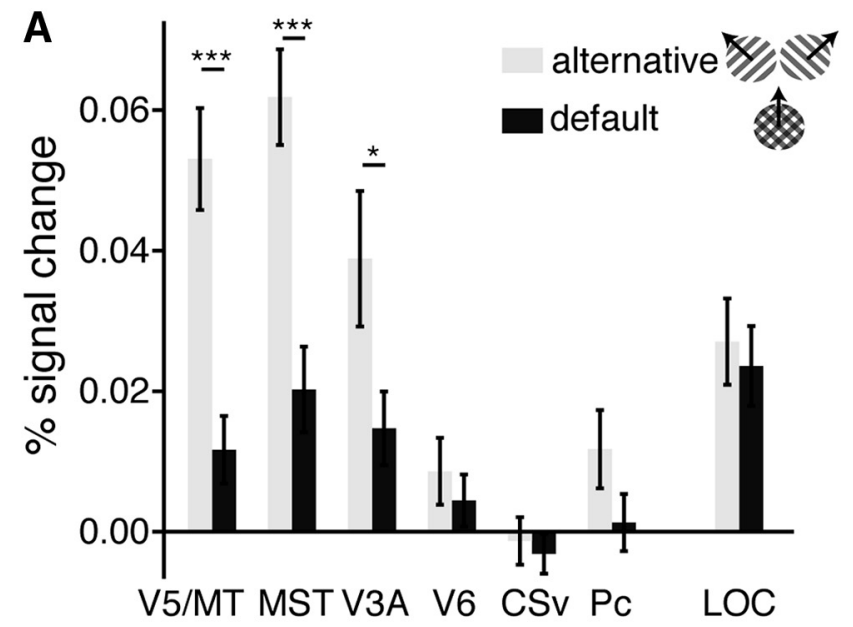

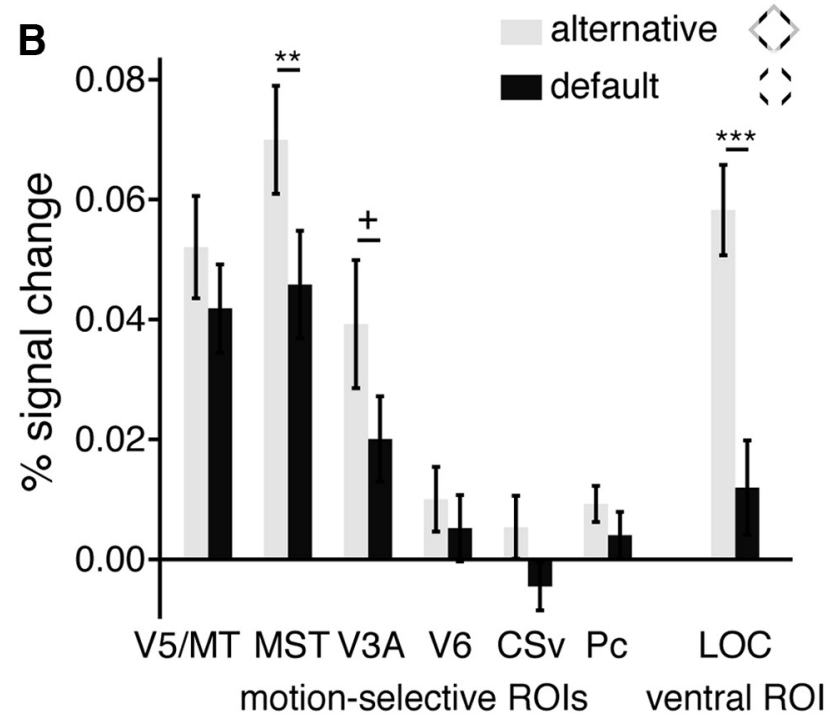

Figure 3. ROI analysis results. Responses of the posterior parietal cortex ROI and early visual cortex ROIs for the plaid $(\boldsymbol{A})$ and diamond $(\boldsymbol{B})$ displays (mean \pm SEM). The PPC showed differential modulation favoring the alternative percept in both stimuli. Early visual areas V1 and V2 were consistently deactivated during perception of the alternative percept in both stimuli. Area V3 revealed no percept-driven modulation. The baseline corresponds to the mean fixation-only response. $C$, Group parietal $R O$ I together with three individual examples of the early visual $R O 1 s$ in MNI space. ${ }^{* * *} p<0.001$; ${ }^{* *} p<0.01$; ${ }^{*} p<0.05$, Holms-Bonferroni corrected; $+p<0.05$, uncorrected.

accompanied with a suppression of early visual areas V1 and V2 during non-default percepts across all stimuli used.

PPC activation

The enhancement of activity in the PPC during non-default interpretations is in line with an increasing number of studies that reported the involvement of the PPC in high-level visual tasks like perceptual grouping (Yokoi and Komatsu, 2009; Zaretskaya et al., 2013; Reichert et al., 2014; Grassi et al., 2016; Liu et al., 2017), motion segmentation (Duarte et al., 2017), object processing (Konen and Kastner, 2008), and 3D form extraction from motion (Orban, 2011). The common denominator in all these vision tasks appears to be scene segmentation: what is foreground and

Figure 4. ROl analysis of the ventral shape selective and dorsal motion selective areas for the plaid $(\boldsymbol{A})$ and diamond $(\boldsymbol{B})$ displays (mean \pm SEM). Responses of dorsal and ventral areas to perceptual changes during viewing of the Gestalt illusion display can be found in our previous work Grassi et al. $(2016,2017)$. None of the regions was consistently up- or down-modulated for a given percept type across all three bistable stimulus classes. ${ }^{* *} p<0.001 ;{ }^{* *} p<0.01 ;{ }^{*} p<$ 0.05 , Holms-Bonferroni corrected; $+p<0.05$, uncorrected.

background, and which visual components belong to the same entity?

The role of the PPC in scene segmentation is likely not constrained to dynamic stimuli. Segmentation tasks based on static displays such as the alternative interpretation of the Schroeder's staircase (Karten et al., 2013), 3D perception of the Necker cube (Inui et al., 2000), and figure completion of Kanizsa displays (M. M. Murray et al., 2002, 2004; Stanley and Rubin, 2003) have all been shown to involve the PPC. Given that in all of the stimuli used here (and in most used in prior literature) the alternative interpretation involved scene segmentation in depth as well as grouping of elements, this could be common function(s) of the PPC segmentation process.

Interestingly, beyond scene segmentation the PPC is also known to play a crucial role in spatial attention and visual selection (Kastner and Ungerleider, 2000; Corbetta and Shulman, 2002). The anatomical convergence of these processes in the PPC points to a functional relationship, including evidence that objects are the units of attentional selection (Qiu et al., 2007; Bartels, 

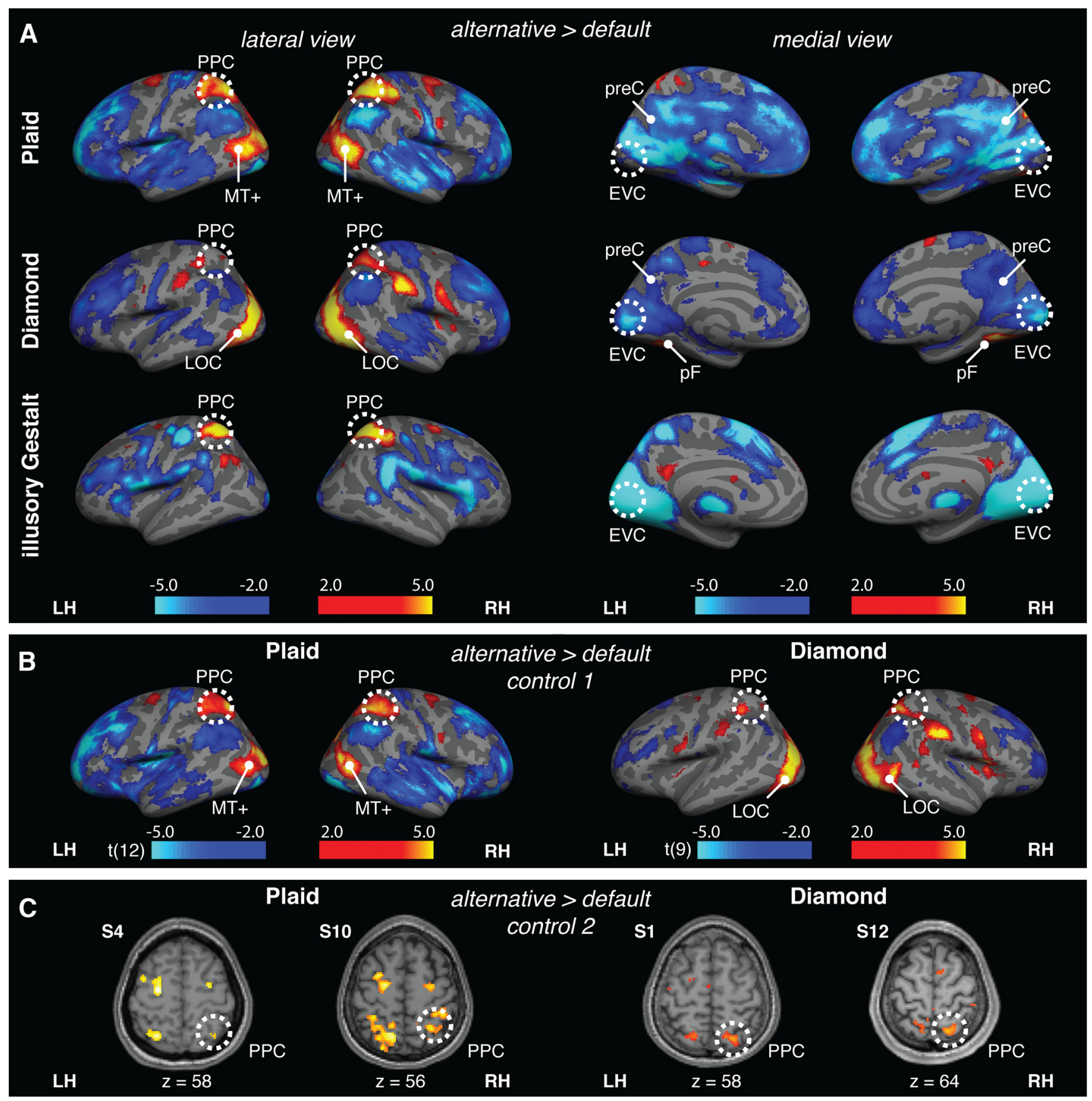

Figure 5. Whole-brain results showing the main contrast alternative $>$ default for all stimulus displays. A, Whole-brain results for the plaid, diamond, and illusory Gestalt displays. Illusory Gestalt results are reproduced here for comparison from the work by Zaretskaya et al., 2013. B, First control analysis: whole-brain results for the plaid and diamond displays testing subjects who reported not to have guided their perception to any particular interpretation of the stimuli (diamond: $n=10$, plaid: $n=13$ ). C, Second control analysis: axial section through PPC for the two participants (S4 and S10) who reported more difficulty in perceiving the default percept for the diamond display, plus an additional two participants (S1 and S12) who reported the same for the plaid display (Table 1) (from the $3 \mathrm{~mm}$ (FWHM) smoothed data; thresholded at $p<0.001$, uncorrected). PPC activity was hence driven by percept type, not by difficulty. Results of $A$ and $B$ are projected onto average inflated cortical hemispheres from the FreeSurfer software (Fischl et al., 1999). For better visualization we thresholded the results at the liberal value of $t=2$. EVC, early visual cortex; LOC, lateral occipital complex; MT+, motion-selective cortex; pF, posterior fusiform gyrus; PPC, posterior parietal cortex; preC, precuneus; LH, left hemisphere; RH, right hemisphere.

2009; Fang et al., 2009; Yokoi and Komatsu, 2009; McMains and Kastner, 2011; Poort et al., 2012). However, the fact that perceptual integration involves parietal cortex even when it is task-irrelevant suggests a degree of independence between perceptual integration and attentional processing (Liu et al., 2017), and the relative suppression of early visual cortex during PPC activation during scene segmentation suggest distinct effects of segmentation and attention on visual cortex. Similarly, our prior evidence that interference with parietal activity selectively reduced durations of the non-default percept in the Gestalt display suggests a causal role of parietal cortex in nondefault percept formation rather than its post hoc activation through the percept change (Zaretskaya et al., 2013). Future studies are needed to investigate whether the same applies for the diamond and plaid displays, whether a single or multiple segmentation processes reside in PPC, and how they interact with other processes such as (voluntary) attention and perceptual selection. 


\section{Conjunction analysis:}
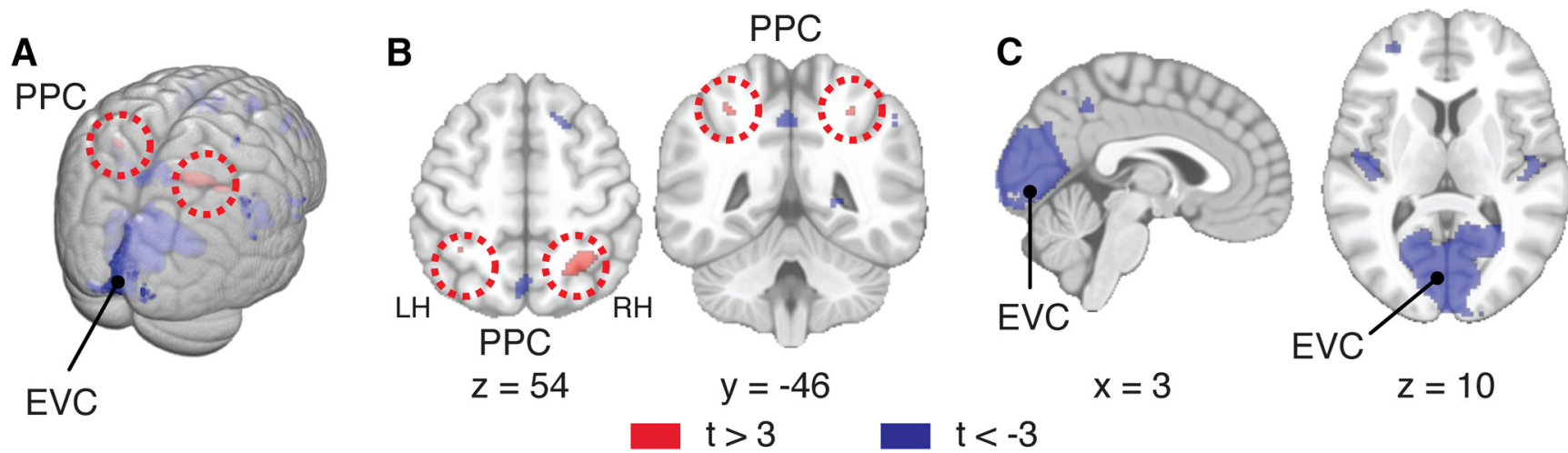

Figure 6. Conjunction analysis. The figure shows overlapping voxels in a glass brain $(\boldsymbol{A})$ and cross-sections $(\boldsymbol{B}, \boldsymbol{C})$ from the contrast alternative $>$ default that reached a threshold of $t>3$ and $t<-3(p<0.005)$ in each of the three display types. Across all three stimuli (plaid, diamond, and illusory Gestalt), we found consistent PPC activation $(\boldsymbol{B})$ and EVC deactivation $(\boldsymbol{C})$ during perception of the non-default interpretation. $\mathrm{LH}$, Left hemisphere; $\mathrm{RH}$, right hemisphere.

\section{Feedback to EVC}

In addition to the role of PPC in motion-based scene segmentation, our results show a consistent down-modulation of V1 and V2 whenever the alternative interpretation was perceived. This is consistent with prior imaging evidence of EVC suppression during viewing of object or Gestalt content (S. O. Murray et al., 2002; Fang et al., 2008; Zaretskaya et al., 2013; Reichert et al., 2014; Grassi et al., 2016). Our results extend these findings to scene segmentation also in the absence of Gestalt.

The early modulation observed here is likely related to electrophysiological evidence of neurons in early visual areas signaling border-ownership (Zhou et al., 2000), illusory contours (Peterhans and von der Heydt, 1989), and filling in of foreground surfaces (Roelfsema et al., 2007). These processes have also been shown to undergo top-down attentional modulation (Fang et al., 2009; Poort et al., 2012), with delayed signal modulation in upper and lower cortical layers known to receive feedback from higherlevel areas (Self et al., 2013). In case of Gestalt displays, perceptual states differentially modulate V1 and V2 in ways that reflect the topographic layout of the alternative percept (Kok and de Lange, 2014; Grassi et al., 2017). Recent laminar signal evidence supports the view that feedback mediates this modulation (Kok et al., 2016). Because the strongest components of these percept-driven EVC modulations were consistently negative for the alternative percept, negative EVC signal would dominate smoothed multisubject analyses.

The consistent involvement of the PPC during perceptual organization makes it a likely contributor to the EVC modulations. This does not rule out additional, stimulus-specific contributors, such as V5+/MT+ and LOC, as has been suggested previously (S. O. Murray et al., 2002; Guo et al., 2004; Schmidt et al., 2011).

The percept-driven EVC modulation is compatible with the theory of predictive coding (Rao and Ballard, 1999; Friston, 2005), and the present data extend experimental evidence to nonGestalt scene segmentation processes.

\section{Numerosity}

In addition to its involvement in attention and perceptual organization, the PPC has also previously been associated with the representation of numerosity (Eger et al., 2003; Harvey et al., 2013). However, the present data show that the consistent upmodulation of PPC with the non-default interpretation cannot be related to numerosity processing or perception: in two of our stimuli, the alternative percept corresponded to a reduction of perceived items (our grouping-related stimuli, i.e., illusory Gestalt display and diamond display), but for the plaid stimulus, the alternative percept corresponded to an increase in perceived items.

\section{Plaid}

One of the surprising findings in this study concerns the plaid stimuli. Traditionally, perception of pattern motion has been seen as the perceptual correlate of advanced neural integration: electrophysiological studies using unambiguous sinewave gratings revealed that neurons in V1 respond only to component motion, whereas pattern motion is processed first in the V5/MT complex (Movshon et al., 1985; Khawaja et al., 2013).

However, there are good reasons to view component motion as a result of late visual segmentation. First, component motion is the more complex perceptual interpretation: rather than a single surface moving in one direction, component motion suggests transparency, 3D arrangement, and two objects gliding over each other independently in two distinct directions.

Second, behaviorally, pattern motion is perceived first, with component motion perception developing later, as observed in the present data as well as previously (Hupé and Rubin, 2003; Hupé and Pressnitzer, 2012).

Third, non-motion surface segmentation cues, such as depth and occlusion, can modulate the perception of motion in the plaid display, suggesting that higher-level integration processes including multiple features are involved (Kersten et al., 1992; Trueswell and Hayhoe, 1993; Stoner and Albright, 1996, 1998).

Finally, the V1 versus V5+/MT+ segregation does no longer apply to rectangular-wave gratings similar to those used in our study, for which V5/MT neurons can change their tuning properties based on transparency cues (Stoner and Albright, 1992).

Our results are consistent with previous fMRI studies that reported a relative deactivation of $\mathrm{V} 5+/ \mathrm{MT}+$ during pattern motion perception (Castelo-Branco et al., 2002; Villeneuve et al., 2012) and a recent study in which pattern motion direction was decoded in V1 (van Kemenade et al., 2014). The increase of activity in the PPC and motion-selective areas during the transparent motion interpretation suggest their involvement in the computationally more demanding segmentation of the two surfaces rather than in the integration of the two components into a 
coherent pattern. This interpretation is consistent with the fMRI results from a recent study that used a similar asymmetric bistable stimulus revealing $\mathrm{V} 5+/ \mathrm{MT}+$ and parietal involvement during the alternative perception of two segmented surfaces moving inward compared with the default perception of one surface moving downward (Duarte et al., 2017).

\section{Diamond}

Most previous fMRI studies that used the diamond display to study grouping of individual elements into coherent shapes focused their analysis on EVC and on LOC (S. O. Murray et al., 2002; Fang et al., 2008; De-Wit et al., 2012). The majority of these studies consistently reported LOC activation together with V1 deactivation during shape compared with element perception and interpreted the differential modulation in context of predictive coding. One further fMRI study using different variations of the diamond display (Caclin et al., 2012) failed to report V1 deactivation, which may be due to differences in the stimulation parameters (De-Wit et al., 2012, their Discussion; Caclin et al., 2012). Our findings extend prior findings to show involvement of PPC during shape perception.

\section{Conclusion}

In sum, we found a consistent PPC activation and EVC deactivation specifically during perception of the alternative interpretations, which consistently involved 3D scene segmentation and grouping, across a range of asymmetric bistable stimuli. Our findings suggest a generic mechanism for late motion-based scene segmentation in the PPC.

\section{References}

Anstis S, Kim J (2011) Local versus global perception of ambiguous motion displays. J Vis 11:13 1-12. CrossRef Medline

Bartels A (2009) Visual perception: converging mechanisms of attention, binding, and segmentation? Curr Biol 19:R300-R302. CrossRef Medline

Brainard DH (1997) The Psychophysics Toolbox. Spatial Vision 10:433-436. CrossRef Medline

Caclin A, Paradis AL, Lamirel C, Thirion B, Artiges E, Poline J, Lorenceau J (2012) Perceptual alternations between unbound moving contours and bound shape motion engage a ventral / dorsal interplay. J Vis 12:11 1-24. CrossRef Medline

Calhoun VD, Stevens MC, Pearlson GD, Kiehl KA (2004) fMRI analysis with the general linear model: removal of latency-induced amplitude bias by incorporation of hemodynamic derivative terms. Neuroimage 22:252257. CrossRef Medline

Cardin V, Smith AT (2010) Sensitivity of human visual and vestibular cortical regions to egomotion-compatible visual stimulation. Cereb Cortex 20:1964-1973. CrossRef Medline

Cardin V, Smith AT (2011) Sensitivity of human visual cortical area V6 to stereoscopic depth gradients associated with self-motion. J Neurophysiol 106:1240-1249. CrossRef Medline

Castelo-Branco M, Formisano E, Backes W, Zanella F, Neuenschwander S, Singer W, Goebel R (2002) Activity patterns in human motion-sensitive areas depend on the interpretation of global motion. Proc Natl Acad Sci U S A 99:13914-13919. CrossRef Medline

Corbetta M, Shulman GL (2002) Control of goal-directed and stimulusdriven attention in the brain. Nat Rev Neurosci 3:201-215. CrossRef Medline

De-Wit LH, Kubilius J, Wagemans J, de Beeck HPO (2012) Bistable gestalts reduce activity in the whole of $\mathrm{V} 1$, not just the retinotopically predicted parts. J Vis 12:pii.12. CrossRef Medline

Duarte JV, Costa GN, Martins R, Castelo-Branco M (2017) Pivotal role of $\mathrm{hMT}+$ in long-range disambiguation of interhemispheric bistable surface motion. Hum Brain Mapp 38:4882-4897. CrossRef Medline

Dumoulin SO, Bittar RG, Kabani NJ, Baker CL Jr, Le Goualher G, Bruce Pike G, Evans AC (2000) A new anatomical landmark for reliable identification of human area V5/MT: a quantitative analysis of sulcal patterning. Cereb Cortex 10:454-463. CrossRef Medline
Eger E, Sterzer P, Russ MO, Giraud AL, Kleinschmidt A (2003) A supramodal number representation in human intraparietal cortex. Neuron 37:719-725. CrossRef Medline

Fang F, Kersten D, Murray SO (2008) Perceptual grouping and inverse fMRI activity patterns in human visual cortex. J Vis 8:2 2-9. CrossRef Medline

Fang F, Boyaci H, Kersten D (2009) Border ownership selectivity in human early visual cortex and its modulation by attention. J Neurosci 29:460465. CrossRef Medline

Fink GR, Halligan PW, Marshall JC, Frith CD, Frackowiak RS, Dolan RJ (1996) Where in the brain does visual attention select the forest and the trees? Nature 382:626-628. CrossRef Medline

Fischer E, Bülthoff HH, Logothetis NK, Bartels A (2012a) Human areas V3A and V6 compensate for self-induced planar visual motion. Neuron 73: 1228-1240. CrossRef Medline

Fischer E, Bülthoff HH, Logothetis NK, Bartels A (2012b) Visual motion responses in the posterior cingulate sulcus: a comparison to V5/MT and MST. Cereb Cortex 22:865-876. CrossRef Medline

Fischl B, Sereno MI, Dale AM (1999) Cortical surface-based analysis: II. Inflation, flattening, and a surface-based coordinate system. Neuroimage 9:195-207. CrossRef Medline

Friston K (2005) A theory of cortical responses. Philos Trans R Soc Lond B Biol Sci 360:815-836. CrossRef Medline

Grassi PR, Zaretskaya N, Bartels A (2016) Parietal cortex mediates perceptual gestalt grouping independent of stimulus size. Neuroimage 133:367377. CrossRef Medline

Grassi PR, Zaretskaya N, Bartels A (2017) Scene segmentation in early visual cortex during suppression of ventral stream regions. Neuroimage 146:7180. CrossRef Medline

Grill-Spector K, Kourtzi Z, Kanwisher N (2001) The lateral occipital complex and its role in object recognition. Vision Res 41:1409-1422. CrossRef Medline

Guo K, Benson PJ, Blakemore C (2004) Pattern motion is present in V1 of awake but not anaesthetized monkeys. Eur J Neurosci 19:1055-1066. CrossRef Medline

Harvey BM, Klein BP, Petridou N, Dumoulin SO (2013) Topographic representation of numerosity in the human parietal cortex. Science 341: 1123-1126. CrossRef Medline

Himmelbach M, Erb M, Klockgether T, Moskau S, Karnath HO (2009) fMRI of global visual perception in simultanagnosia. Neuropsychologia 47:1173-1177. CrossRef Medline

Huk AC, Ress D, Heeger DJ (2001) Neuronal basis of the motion aftereffect reconsidered. Neuron 32:161-172. CrossRef Medline

Huk AC, Dougherty RF, Heeger DJ (2002) Retinotopy and functional subdivision of human areas MT and MST. J Neurosci 22:7195-7205. CrossRef Medline

Hupé JM, Rubin N (2003) The dynamics of bi-stable alternation in ambiguous motion displays: a fresh look at plaids. Vision Res 43:531-548. CrossRef Medline

Hupé JM, Pressnitzer D (2012) The initial phase of auditory and visual scene analysis. Philos Trans R Soc Lond B Biol Sci 367:942-953. CrossRef Medline

Hupé JM, Rubin N (2004) The oblique plaid effect. Vision Res 44:489-500. CrossRef Medline

Inui T, Tanaka S, Okada T, Nishizawa S, Katayama M, Konishi J (2000) Neural substrates for depth perception of the Necker cube; a functional magnetic resonance imaging study in human subjects. Neurosci Lett 282: 145-148. CrossRef Medline

Karnath HO, Ferber S, Rorden C, Driver J (2000) The fate of global information in dorsal simultanagnosia. Neurocase 6:295-306. CrossRef

Karten A, Pantazatos SP, Khalil D, Zhang X, Hirsch J (2013) Dynamic coupling between the lateral occipital-cortex, default-mode, and frontoparietal networks during bistable perception. Brain Connect 3:286-293. CrossRef Medline

Kastner S, Ungerleider LG (2000) Mechanisms of visual attention in the human cortex. Annu Rev Neurosci 23:315-341. CrossRef Medline

Kersten D, Bülthoff HH, Schwartz BL, Kurtz KJ (1992) Interaction between transparency and structure from motion. Neural Comput 4:573-589. CrossRef

Khawaja FA, Liu LD, Pack CC (2013) Responses of MST neurons to plaid stimuli. J Neurophysiol 110:63-74. CrossRef Medline

Kleiner M, Brainard D, Pelli D, Broussard C (2007) What's new in Psychtoolbox-3? Perception 36:1-16. CrossRef

Kok P, de Lange FP (2014) Shape perception simultaneously up- and down- 
regulates neural activity in the primary visual cortex. Curr Biol 24:15311535. CrossRef Medline

Kok P, Bains LJ, van Mourik T, Norris DG, De Lange FP (2016) Selective activation of the deep layers of the human primary visual cortex by topdown feedback. Curr Biol 26:371-376. CrossRef Medline

Kolster H, Peeters R, Orban GA (2010) The retinotopic organization of the human middle temporal area MT/V5 and its cortical neighbors. J Neurosci 30:9801-9820. CrossRef Medline

Konen CS, Kastner S (2008) Two hierarchically organized neural systems for object information in human visual cortex. Nat Neurosci 11:224-231. CrossRef Medline

Liu L, Wang F, Zhou K, Ding N, Luo H (2017) Perceptual integration rapidly activates dorsal visual pathway to guide local processing in early visual areas. PLoS Biol 15:e2003646. CrossRef Medline

Lorenceau J, Shiffrar M (1992) The influence of terminators on motion integration across space. Vision Res 32:263-273. CrossRef Medline

Luria AR (1959) Disorders of "simultaneous perception" in a case of bilateral occipito-parietal brain injury. Brain 82:437-449. CrossRef Medline

McMains S, Kastner S (2011) Interactions of top-down and bottom-up mechanisms in human visual cortex. J Neurosci 31:587-597. CrossRef Medline

Mevorach C, Humphreys GW, Shalev L (2006) Opposite biases in saliencebased selection for the left and right posterior parietal cortex. Nat Neurosci 9:740-742. CrossRef Medline

Movshon JA, Adelson EH, Gizzi MS, Newsome WT (1985) The analysis of moving visual patterns (Chagas C, Gattass R, Gross C, eds). Pattern Re, Rome: Vatican.

Muckli L, Kohler A, Kriegeskorte N, Singer W (2005) Primary visual cortex activity along the apparent-motion trace reflects illusory perception. PLoS Biol 3:e265. CrossRef Medline

Murray MM, Wylie GR, Higgins BA, Javitt DC, Schroeder CE, Foxe JJ (2002) The spatiotemporal dynamics of illusory contour processing: combined high-density electrical mapping, source analysis, and functional magnetic resonance imaging. J Neurosci 22:5055-5073. CrossRef Medline

Murray MM, Foxe DM, Javitt DC, Foxe JJ (2004) Setting boundaries: brain dynamics of modal and amodal illusory shape completion in humans. J Neurosci 24:6898-6903. CrossRef Medline

Murray SO, Kersten D, Olshausen BA, Schrater P, Woods DL (2002) Shape perception reduces activity in human primary visual cortex. Proc Natl Acad Sci U S A 99:15164-15169. CrossRef Medline

Murray SO, Olshausen BA, Woods DL (2003) Processing shape, motion and three-dimensional shape-from-motion in the human cortex. Cereb Cortex 13:508-516. CrossRef Medline

Nelissen K, Vanduffel W, Orban GA (2006) Charting the lower superior temporal region, a new motion-sensitive region in monkey superior temporal sulcus. J Neurosci 26:5929-5947. CrossRef Medline

Orban GA (2011) The extraction of 3D shape in the visual system of human and nonhuman primates. Annu Rev Neurosci 34:361-388. CrossRef Medline

Paradis AL, Cornilleau-Pérès V, Droulez J, Van De Moortele PF, Lobel E, Berthoz A, Le Bihan D, Poline JB (2000) Visual perception of motion and 3-D structure from motion: an fMRI study. Cereb Cortex 10:772783. CrossRef Medline

Pelli DG (1997) The VideoToolbox software for visual psychophysics: Transforming numbers into movies. Spatial Vision 10:437-442. CrossRef Medline

Pernet CR (2014) Misconceptions in the use of the general linear model applied to functional MRI: a tutorial for junior neuro-imagers. Front Neurosci 8:1-12. CrossRef Medline

Peterhans E, von der Heydt R (1989) Mechanisms of contour perception in monkey visual cortex: II. Contours bridging gaps. J Neurosci 9:17491763. CrossRef Medline

Pitzalis S, Galletti C, Huang RS, Patria F, Committeri G, Galati G, Fattori P, Sereno MI (2006) Wide-field retinotopy defines human cortical visual area v6. J Neurosci 26:7962-7973. CrossRef Medline

Pitzalis S, Sereno MI, Committeri G, Fattori P, Galati G, Tosoni A, Galletti C (2013) The human homologue of macaque area V6A. Neuroimage 82: 517-530. CrossRef Medline

Pitzalis S, Fattori P, Galletti C (2015) The human cortical areas V6 and V6A. Vis Neurosci 32:E007. CrossRef Medline

Poort J, Raudies F, Wannig A, Lamme VA, Neumann H, Roelfsema PR
(2012) The role of attention in figure-ground segregation in areas V1 and V4 of the visual cortex. Neuron 75:143-156. CrossRef Medline

Qiu FT, Sugihara T, von der Heydt R (2007) Figure-ground mechanisms provide structure for selective attention. Nat Neurosci 10:1492-1499. CrossRef Medline

Rao RP, Ballard DH (1999) Predictive coding in the visual cortex: a functional interpretation of some extra-classical receptive-field effects. Nat Neurosci 2:79-87. CrossRef Medline

Reichert C, Fendrich R, Bernarding J, Tempelmann C, Hinrichs H, Rieger JW (2014) Online tracking of the contents of conscious perception using real-time fMRI. Front Neurosci 8:116. CrossRef Medline

Roelfsema PR, Tolboom M, Khayat PS (2007) Different processing phases for features, figures, and selective attention in the primary visual cortex. Neuron 56:785-792. CrossRef Medline

Romei V, Driver J, Schyns PG, Thut G (2011) Rhythmic TMS over parietal cortex links distinct brain frequencies to global versus local visual processing. Curr Biol 21:334-337. CrossRef Medline

Schmidt KE, Lomber SG, Payne BR, Galuske RA (2011) Pattern motion representation in primary visual cortex is mediated by transcortical feedback. Neuroimage 54:474-484. CrossRef Medline

Self MW, van Kerkoerle T, Supèr H, Roelfsema PR (2013) Distinct roles of the cortical layers of area V1 in figure-ground segregation. Curr Biol 23:2121-2129. CrossRef Medline

Smith AT, Wall MB, Williams AL, Singh KD (2006) Sensitivity to optic flow in human cortical areas MT and MST. Eur J Neurosci 23:561-569. CrossRef Medline

Stanley DA, Rubin N (2003) fMRI activation in response to illusory contours and salient regions in the human lateral occipital complex. Neuron 37:323-331. CrossRef Medline

Steffener J, Tabert M, Reuben A, Stern Y (2010) Investigating hemodynamic response variability at the group level using basis functions. Neuroimage 49:2113-2122. CrossRef Medline

Stoner GR, Albright TD (1992) Neural correlates of perception motion coherence. Nature 358:412-414. CrossRef Medline

Stoner GR, Albright TD (1996) The interpretation of visual motion: evidence for surface segmentation mechanisms. Vision Res 36:1291-1310. CrossRef Medline

Stoner GR, Albright TD (1998) Luminance contrast affects motion coherence in plaid patterns by acting as a depth-from-occlusion cue. Vision Res 38:387-401. CrossRef Medline

Stoner GR, Albright TD, Ramachandran VS (1990) Transparency and coherence in human motion perception. Nature 344:153-155. CrossRef Medline

Trueswell JC, Hayhoe MM (1993) Surface segmentation mechanisms and motion perception. Vision Res 33:313-328. CrossRef Medline

van Kemenade BM, Seymour K, Christophel TB, Rothkirch M, Sterzer P (2014) Decoding pattern motion information in V1. Cortex 57:177-187. CrossRef Medline

Villeneuve MY, Kupers R, Gjedde A, Ptito M, Casanova C (2005) Patternmotion selectivity in the human pulvinar. Neuroimage 28:474-480. CrossRef Medline

Villeneuve MY, Thompson B, Hess RF, Casanova C (2012) Pattern-motion selective responses in MT, MST and the pulvinar of humans. Eur J Neurosci 36:2849-2858. CrossRef Medline

Wall MB, Smith AT (2008) The representation of egomotion in the human brain. Curr Biol 18:191-194. CrossRef Medline

Wang L, Mruczek RE, Arcaro MJ, Kastner S (2015) Probabilistic maps of visual topography in human cortex. Cereb Cortex 25:3911-3931. CrossRef Medline

Wolpert I (1924) Die simultanagnosie: störung der gesamtauffassung. Z Gesamte Neurol Psychiatr 93:397-415. CrossRef

Yokoi I, Komatsu H (2009) Relationship between neural responses and visual grouping in the monkey parietal cortex. J Neurosci 29:13210-13221. CrossRef Medline

Zaretskaya N, Anstis S, Bartels A (2013) Parietal cortex mediates conscious perception of illusory gestalt. J Neurosci 33:523-531. CrossRef Medline

Zeki S, Stutters J (2013) Functional specialization and generalization for grouping of stimuli based on colour and motion. Neuroimage 73:156166. CrossRef Medline

Zhou H, Friedman HS, von der Heydt R (2000) Coding of border ownership in monkey visual cortex. J Neurosci 20:6594-6611. CrossRef Medline 